\title{
AGGRESSION AT THE WORKPLACE - PSYCHOLOGICAL CONSEQUENCES OF ABUSIVE ENCOUNTER WITH COWORKERS AND CLIENTS
}

\section{DOROTA MERECZ, MARCIN DRABEK, and AGNIESZKA MOŚCICKA}

Nofer Insitute of Occupational Medicine, Łódź, Poland

Department of Work Psychology

\begin{abstract}
Objectives: The aim of the study was to evaluate the consequences of the exposure to workplace aggression from coworkers and clients. Materials and Methods: Participants belonged to two professional groups: nurses ( $N=1163$ ) and public service workers $(\mathrm{N}=391)$. Aggression from coworkers and clients/patients was analysed separately. Several multiple regression models were tested to assess the effect of work-related aggression experienced by the subjects on their job satisfaction, professional functioning and mental health status. The frequency and type of violent behaviours against employee was measured by Exposure to Workplace Aggression Questionnaire (EWAQ), level of burnout was determined by Maslach Burnout Inventory (MBI), mental health status by General Health Questionnaire (GHQ-28), and the level of work satisfaction was measured by 22-items survey, developed at NIOM Work Psychology Department. In the regression models, several possible confounders were controlled (sex, age, individual direct reaction to aggressive act, and physical health status). Results: Results of our study point to adverse consequences of exposure to aggression at workplace, irrespective of its source. Employees experiencing workplace aggression are less satisfied with work, show symptoms of burnout, and their general health is poorer. Conclusion: We assume that aggression towards coworkers by peers and supervisors, as the phenomenon reflecting quality of long term interpersonal relationships, may affect health and functioning of workers stronger than a single incident in the short term contacts with clients. Aggression from clients usually results in compassion of peers, and it is perceived as the organisational problem that should be solved. On the contrary, dealing with an aggressive coworker usually is perceived as employee's own business and results in the sense of unfairness and isolation.
\end{abstract}

Key words:

Workplace aggression, Job satisfaction, Mental health, Burnout

\section{INTRODUCTION}

Since technological changes have been introduced in most branches of economy, the exposure to classical risk factors at workplace was significantly reduced. In most well developed countries technology effectively helps in protecting employees' health from various biological, chemical and physical harms. Since early 80 's more and more attention is paid at the role of soft factors, such as psychosocial stressors at work which are thought to affect employees' occupational functioning and health. Recently, especially aggression at workplace and its consequences are in the scope of interest of both scientists and practitioners. The area of research studies includes exposure to single aggressive acts, long lasting violence, such as mobbing or sexual harassment, organisational and individual risk factors, and psychological and socioeconomical consequences of exposure to violent behaviours. Taking into consideration aggression after-effects, deteriorated health and decreased productivity of the exposed employee may be quoted as major examples. The first sphere affected by aggression is the psyche. For the victim, each interaction with the offender is a source of stress and, in long-term perspective, causes mental health disorders and stress-related somatic symptoms. Traditionally, negative effects of exposure to aggression may

Received: June 26, 2009. Accepted: August 18, 2009.

Address request reprint to D. Merecz, Zakład Psychologii Pracy, Instytut Medycyny Pracy im. prof. J. Nofera, św. Teresy 8, 91-348 Lódź (e-mail: merecz@imp.lodz.pl) 
be divided into two subcategories: direct effects presented immediately after aggressive social interaction, and long-term effects, usually consequences of repeated exposure [1]. Direct effects of aggressive encounters reflect mostly in emotional sphere - victims frequently report feelings of irritations, anger, anxiety, helplessness, depression, discouragement, felling of guilt, and decreased self-esteem. If aggression is frequent or very intense and abusive, the emotional reactions quoted above may increase and lead to development of chronic mental health impairment, such as mood and anxiety disorders, addictions, or suicidal attempts [1-5]. Victims of prolonged or frequent interpersonal violence experience also wide range of somatic symptoms, such as headaches, recurrent migraines, gastric problems, vomiting, insomnia and other sleep disorders, painful muscle tension, and decreased libido [1-4,6]. Long-term exposure to workplace aggression leads to an impairment of social and professional life - relationships with coworkers are changed - the number of interpersonal conflicts increases, motivation and work involvement decreases [2-6]. We may observe also changes in attitudes towards company leaders mostly distrust to managerial staff, resulting from the sense of threat experienced by victims, adversely affecting victims' productivity and their willingness to comply to the professional ethical standards [7]. Some researchers underline economic costs of aggression at the workplace: costs of medical care for the sufferers, legal costs and expenses due to personnel changes, absenteeism, and premature retirement [5]. Violent behaviours in the workplace generate additional costs for employers. These costs are not taken into account in Poland (no calculations of any aggression-related costs has been attempted up to now) but, for example, American experts estimate that merely the costs of aggression-related absenteeism may be as high as 55 million dollars per year $[2,8]$. Nowadays in Europe one may observe large amount of scientific, legal and practical initiatives aimed at development of good practice in aggression prevention at the workplace. In Poland we are at the beginning on this way. What we need is to build awareness that aggression is harmful and costly not only for people affected but also for the society in general. There is a need for developing standards for monitoring of various forms of aggression at the workplace and providing standards for an effective prevention. Scientific research studies sensitive to national specificity should serve as the background for the above mentioned activities.

The paper summarises the results of two studies conducted in health care and public service sectors. The aim of these studies was estimation of possible relations between frequency of exposure to aggression and mental health status and work functioning of affected employees. Several hypotheses were formulated:

H1: More frequent exposure to aggressive behaviours of other people is related to decreased work satisfaction,

$\mathrm{H} 2$ : More frequent exposure to aggressive behaviours of other people is related to presence of burnout symptoms H3: More frequent exposure to aggressive behaviours of other people is related to lower mental health status.

As two sources of aggression at the workplace: (a) client/ patient aggression towards employees, and (b) employees' aggressive encounters were analysed, a general question was formulated: Does the aggression experienced from coworkers exert the same effect on well being and professional functioning as aggression experienced from clients/ patients?

\section{MATERIALS AND METHODS}

\section{Subjects}

The study comprised two general categories of employees: health care workers (nurses) and service workers (transport and post service). The choice of those groups was intentional - international data show that these sectors are at risk of increased aggression exposure [9]. The elevated risk of aggression in these professional groups is related to specific character of work itself. In these sectors, permanent contacts with clients/patients is the important content of work duties. Moreover, work organisation, staff shortages and many other limitations produce additional tensions and lead to feeling of frustration, anger both in clients and workers. Additionally, working at evening/ night hours or alone, quite frequent in these professions, 
Table 1. Basic statistics for age and years of professional experience in groups under study

\begin{tabular}{|c|c|c|c|c|c|c|c|c|c|c|c|c|}
\hline \multirow{2}{*}{ Variable } & \multicolumn{6}{|c|}{ Nurses $(\mathrm{N}=1163)$} & \multicolumn{6}{|c|}{ Public service workers $(\mathrm{N}=391)$} \\
\hline & $\bar{x}$ & $\mathrm{SD}$ & $\min$ & $\max$ & $g_{1}$ & $\mathrm{~g}_{2}$ & $\bar{x}$ & $\mathrm{SD}$ & $\min$ & $\max$ & $g_{1}$ & $\mathrm{~g}_{2}$ \\
\hline Age & 38.83 & 8.49 & 19.00 & 63.00 & 0.25 & -0.69 & 40.25 & 8.48 & 21.00 & 59.00 & -0.07 & -0.64 \\
\hline $\begin{array}{l}\text { Years of professional } \\
\text { experience }\end{array}$ & 17.44 & 8.93 & 1.00 & 48.00 & 0.22 & -0.63 & 21.00 & 8.85 & 1.00 & 42.00 & -0.25 & -0.49 \\
\hline
\end{tabular}

$\bar{x}$ - arithmetic mean; SD — standard deviation; min — minimum; max — maximum; $\mathrm{g}_{1}$ — skewness; $\mathrm{g}_{2}$ - kurtosis.

may be considered as another factor contributing to the risk of aggression.

The first group under study — health care sector workers - comprised 1163 nurses. This group was a representative sample of nurses in terms of employment pattern.

The second group under study - service sector workers - comprised 226 post office workers and 165 transport workers.

In both groups the inclusion criterion was minimum a year of professional experience.

Participation in the study was voluntary. Participants were asked to fill in a set of questionnaires at home and return them at a fixed day to the researcher. Basic statistics for age and years of professional experience in groups under study are presented in Table 1.

\section{Variables and diagnostic methods}

Exposure to workplace aggression

Workplace aggression has been defined as "any act against an employee that creates a hostile work environment and adversely affects the employee, either physically or psychologically. These acts include all types of physical or verbal assault, threats, coercion, intimidation, and all forms of harassment [10]".

Exposure to Workplace Aggression Questionnaire (EWAQ) was used to evaluate the frequency and type of violent behaviours against employee (see Appendix 1). The survey consists of two parts preceded by instructions for subjects. The first part includes questions dealing with frequency and forms of clients'/patients' aggression against the staff. The second part is dedicated to organisational aggression (coworkers, supervisors and subordinates). Each part consists of eight questions about aggression, from verbal to physical. Subjects are asked to answer how often they are faced with these eight forms of aggressive behaviours at work ( 0 - it does not apply to my work position, 1 - it never happened, to 6 - it happened everyday).

The questionnaire was developed by the authors of this work. Psychometric properties are satisfactory - Cronbach's alpha for the whole scale is 0.89 .

\section{Well-being}

Well-being is a broad concept in health psychology, usually defined as a state of experiencing pleasant emotions, low level of negative mood, sense of-self-efficacy, life satisfaction and being in a good shape [11].

Well-being was assessed by means of General Health Questionnaire (GHQ-28). The following groups of symptoms were taken into account: somatic complains, anxiety and insomnia, disturbances in daily functioning and depression. The questionnaire enables evaluation of current mental health status [12].

\section{Burnout}

Burnout is defined here as a three-component syndrome of emotional exhaustion, depersonalisation and diminished personal accomplishment experienced due to work performed [13]

Level of burnout was measured by Maslach Burnout Inventory (MBI) [14]. The MBI is designed to assess the three components of the burnout syndrome: emotional exhaustion, depersonalisation, and reduced personal accomplishment. There are 22 items, which are divided into three subscales. The 22 items are answered in terms of the frequency on a 7-point, fully anchored scale (ranging from 0 , "never" to 6, "every day"). Psychometric proprieties of the Polish version of the MBI are satisfactory [15]. 


\section{Work satisfaction}

Work satisfaction is defined here as the degree to which people like their jobs [16].

The level of work satisfaction was measured by 22-item survey, developed at the Work Psychology Department of NIOM. The items describe basic work characteristics as for example interpersonal relation at work, relation with clients/patients, resolution of conflicts, quality of relations between managerial staff and subordinates, organisational climate. The subject is asked to evaluate his/her own level of satisfaction from each listed 22 aspects of work. Total score obtained describes the level of general work satisfaction.

Direct reactions to aggressive behaviours (DRAB)

DRAB are understood as direct immediate response to abusive encounter that may appear in one of following forms: aggressive reaction, submissive reaction or assertive reaction.

Direct reactions to aggressive behaviours were assessed by means of Reaction To Aggression Questionnaire developped by Mościcka, Merecz, Drabek (in press). The 15item tool enables assessment of typical reactions to aggressive behaviour: submissive, aggressive and assertive.

Subjects were also asked about their physical health status. Participants evaluated their own health status in comparison to other people at the same age at 5 point response scale from 1 - "very good" to 5 "very poor".

The basic socio-demographic data were also collected from subjects under study.

\section{Statistical analysis}

The statistical analysis of collected data was made with the use of the Statistica software. Regression analyses were performed to assess the possible relations between aggression experienced and outcome measures. Some confounders were controlled in each regression model (age, sex, somatic health status in self-assessment, typical individual direct reaction to aggression: submissive, aggressive or assertive). Due to limited space, the role of confounders will not be discussed in detail, and the focus will be on direct aggression effects on health and professional functioning.

\section{RESULTS}

\section{Exposure to aggression}

The data obtained in the study do not differ much from data collected in other European countries. Detailed information on frequency of aggressive behaviours against the staff was presented elsewhere [17].

Significant number of nurses under study has experienced, during a year before examination, various forms of verbal aggression - mainly loud voice communication and scream. This way of behaving was common for both clients and coworkers; however, verbal aggression presented by clients was much more prevalent. Incidents of physical aggression were not such frequent, but still around $1 / 3$ of nurses reported physical aggression from clients. Among this group, nearly $2 \%$ of subjects had to deal with attempted physical attack more than a couple times a week, and another $2 \%$ experienced direct physical aggression more than a couple times a month. Besides, another $2 \%$ of nurses experienced physical aggression from other staff members.

Similar tendencies in prevalence of aggressive acts at work environment was observed among public transport workers (mainly drivers). As much as $90 \%$ of them reported incidents of verbal abuse from clients and $2 \%$ were targets of physical aggression. Similarly to nurses, public service workers face client's aggression more often than aggression from other staff members; however, the proportion of the workers verbally abused by coworkers was still very high (52\%). The more common type of aggression is verbal aggression presented by clients. It was experienced by $24-50 \%$ of service workers, depending on the character of single acts, while the frequency of aggression experienced from coworkers varied from 4 to $50 \%$ [17].

Mental health status of subjects under study measured by the GHQ-28 general score compared to the relevant standards for Polish working population does not differ from average population score. Mean scores in the GHQ-28 obtained in the two groups of subjects do not 
Table 2. Basic statistics for mental health (GHQ-28), somatic symptoms (GHQ-A), anxiety/insomnia (GHQ-B), social dysfunction (GHQ-C) and depression symptoms (GHQ-D) in groups under study

\begin{tabular}{|c|c|c|c|c|c|c|c|c|c|c|c|c|}
\hline \multirow{2}{*}{ Variable } & \multicolumn{6}{|c|}{ Nurses $(\mathrm{N}=1163)$} & \multicolumn{6}{|c|}{ Public service workers $(\mathrm{N}=391)$} \\
\hline & $\bar{x}$ & SD & $\min$ & $\max$ & $\mathrm{g}_{1}$ & $\mathrm{~g}_{2}$ & $\bar{x}$ & SD & $\min$ & $\max$ & $\mathrm{g}_{1}$ & $\mathrm{~g}_{2}$ \\
\hline GHQ-28 & 24.35 & 11.96 & 0.00 & 83.00 & 1.26 & 2.22 & 23.30 & 11.60 & 2.00 & 64.00 & 1.25 & 1.63 \\
\hline GHQ-A & 7.27 & 4.10 & 0.00 & 21.00 & 0.71 & 0.05 & 7.03 & 4.03 & 0.00 & 21.00 & 0.99 & 0.87 \\
\hline GHQ-B & 7.43 & 4.61 & 0.00 & 21.00 & 0.71 & 0.02 & 6.71 & 4.39 & 0.00 & 21.00 & 0.81 & 0.40 \\
\hline GHQ-C & 7.30 & 2.66 & 0.00 & 21.00 & 1.22 & 4.63 & 7.23 & 2.57 & 0.00 & 17.00 & 0.79 & 2.29 \\
\hline GHQ-D & 2.35 & 3.56 & 0.00 & 21.00 & 2.32 & 6.17 & 2.40 & 3.51 & 0.00 & 20.00 & 2.16 & 5.21 \\
\hline
\end{tabular}

Abbreviations as in Table 1.

Table 3. Basic statistics for job satisfaction, depersonalisation, emotional exhaustion and sense of personal accomplishment in groups under study

\begin{tabular}{|c|c|c|c|c|c|c|c|c|c|c|c|c|}
\hline \multirow{2}{*}{ Variable } & \multicolumn{6}{|c|}{ Nurses $(\mathrm{N}=1163)$} & \multicolumn{6}{|c|}{ Public service workers $(\mathrm{N}=391)$} \\
\hline & $\bar{x}$ & SD & $\min$ & $\max$ & $\mathrm{g}_{1}$ & $\mathrm{~g}_{2}$ & $\bar{x}$ & SD & $\min$ & $\max$ & $\mathrm{g}_{1}$ & $\mathrm{~g}_{2}$ \\
\hline Job satisfaction & 77.55 & 18.65 & 10.00 & 128.00 & -0.46 & 0.22 & 77.93 & 20.28 & 7.00 & 132.00 & -0.49 & 0.40 \\
\hline Depersonalisation & 4.76 & 4.94 & 0.00 & 30.00 & 1.58 & 2.88 & 6.48 & 5.82 & 0.00 & 25.00 & 1.25 & 1.21 \\
\hline Emotional exhaustion & 20.61 & 11.52 & 0.00 & 54.00 & 0.51 & -0.45 & 20.76 & 12.84 & 0.00 & 119.00 & 1.57 & 8.06 \\
\hline $\begin{array}{l}\text { Sense of personal } \\
\text { accomplishment }\end{array}$ & 32.49 & 9.16 & 0.00 & 48.00 & -0.54 & 0.13 & 31.45 & 11.53 & 2.00 & 48.00 & -0.56 & -0.58 \\
\hline
\end{tabular}

Abbreviations as in Table 1.

differ significantly. Basic statistics for these results are presented in Table 2.

The mean values for the burnout dimensions and job satisfaction are also moderate. The groups do not differ significantly in terms of job satisfaction, emotional exhaustion and personal accomplishment. There is significant difference in depersonalisation score of the MBI (Student's $\mathrm{t}=5.69 ; \mathrm{p}<0.000)($ Table 3$)$.

Table 4. Stepwise (forward) multiple linear regression model for relation between aggression from clients/patients and job satisfaction

\begin{tabular}{|c|c|c|c|c|}
\hline Step & Independent variable & Beta & $\mathrm{R}^{2}$ & $\mathrm{~F}^{*}$ \\
\hline \multicolumn{5}{|c|}{ Public service workers } \\
\hline 1 & Aggression from clients & -0.290 & 0.111 & 37.765 \\
\hline 2 & Aggressive reaction & -0.160 & 0.153 & 27.227 \\
\hline \multirow[t]{2}{*}{3} & Assertive reaction & 0.152 & 0.176 & 21.475 \\
\hline & Physical health, Sex, Submissive reaction, Age & n.s. & 0.192 & 10.085 \\
\hline \multicolumn{5}{|c|}{ Nurses } \\
\hline 1 & Physical health & -0.148 & 0.040 & 45.196 \\
\hline 2 & Aggression from patients & -0.152 & 0.059 & 34.361 \\
\hline 3 & Aggressive reaction & -0.126 & 0.080 & 31.745 \\
\hline \multirow[t]{2}{*}{4} & Assertive reaction & 0.065 & 0.086 & 25.591 \\
\hline & Submissive reaction, Age & n.s. & 0.090 & 17.858 \\
\hline
\end{tabular}

n.s. - statistically not significant.

Statistically significant, $\mathrm{p}<0.0000$. 
Table 5. Stepwise (forward) multiple linear regression model for relation between aggression from coworkers and job satisfaction

\begin{tabular}{llccc}
\hline Step & \multicolumn{1}{c}{ Independent variable } & Beta & $\mathrm{R}^{2}$ & $\mathrm{~F}^{*}$ \\
\hline Public service workers & & & \\
1 & Aggression from coworkers & -0.289 & 0.121 & 41.918 \\
2 & Assertive reaction & 0.160 & 0.157 & 28.163 \\
3 & Aggressive reaction & -0.124 & 0.172 & 20.879 \\
& Physical health, Sex, Age, Submissive reaction & n.s. & 0.185 & 9.646 \\
Nurses & & & \\
1 & Aggression from coworkers & -0.270 & 0.100 & 114.001 \\
2 & Physical health & -0.142 & 0.126 & 74.381 \\
3 & Aggressive reaction & -0.100 & 0.139 & 55.229 \\
& Submissive reaction, Assertive reaction, Age & n.s. & 0.144 & 28.829 \\
\hline
\end{tabular}

Abbreviations as in Table 4.

\section{Effects of aggression on well-being and professional functioning (work satisfaction and burnout)}

Several multiple regression models were tested to assess the effect of aggression experienced due to work performed on well-being and professional functioning. It was assumed that both clients'patients' and coworkers' aggression towards employees would result in significant decrease of mental health status and work satisfaction indicators and increase the level of professional burnout. In the regression models, several potential confounders were controlled (sex, age, individual direct reaction to aggressive act, and physical health). The role of these variables in relation between aggression at work and health and functioning at work is discussed elsewhere. Summaries of multiple regression analyses performed are presented in Tables 4 and 5.

As we have assumed, experience of aggression at work, whatever the source of aggression, adversely influences mental health status, work satisfaction and contributes to burnout level.

Aggression from clients/patients explains $11.1 \%$ of variance in work satisfaction of public sector workers and $2.4 \%$ of variance of results in work satisfaction scale in the group of nurses. Coworkers' aggression accounted for $12.1 \%$ of

Table 6. Stepwise (forward) multiple linear regression model for relation between aggression from clients/patients and depersonalisation

\begin{tabular}{llccc}
\hline \multicolumn{1}{c}{ Step } & \multicolumn{1}{c}{ Independent variable } & Beta & $\mathrm{R}^{2}$ & $\mathrm{~F}^{*}$ \\
\hline Public service workers & & & \\
1 & Aggression from clients & 0.416 & 0.223 & 87.170 \\
2 & Assertive reaction & -0.192 & 0.300 & 64.720 \\
3 & Aggressive reaction & 0.184 & 0.333 & 50.159 \\
4 & Sex & 0.144 & 0.348 & 39.986 \\
5 & Submissive reaction & 0.130 & 0.365 & 34.353 \\
\multicolumn{2}{l}{ Physical health, Age } & n.s. & 0.369 & 24.870 \\
Nurses & & & \\
1 & Aggression from patients & 0.280 & 0.080 & 94.665 \\
2 & Aggressive reaction & 0.211 & 0.146 & 93.183 \\
3 & Submissive reaction & 0.111 & 0.165 & 71.591 \\
4 & Physical health & 0.110 & 0.178 & 59.087 \\
5 & Assertive reaction & -0.087 & 0.186 & 49.742 \\
& Age & n.s. & 0.188 & 41.960 \\
\hline
\end{tabular}

Abbreviations as in Table 4. 
Table 7. Stepwise (forward) multiple linear regression model for relation between aggression from coworkers and depersonalisation

\begin{tabular}{llccc}
\hline \multicolumn{1}{c}{ Step } & Independent variable & Beta & $\mathrm{R}^{2}$ & $\mathrm{~F}^{*}$ \\
\hline Public service workers & & & \\
1 & Aggression from coworkers & 0.322 & 0.176 & 64.940 \\
2 & Assertive reaction & -0.198 & 0.251 & 50.615 \\
3 & Aggressive reaction & 0.148 & 0.269 & 36.992 \\
4 & Sex & 0.135 & 0.279 & 29.065 \\
5 & Submissive reaction & 0.129 & 0.294 & 24.949 \\
& Physical health, Age & n.s. & 0.298 & 18.019 \\
Nurses & & & \\
1 & Aggressive reaction & 0.169 & 0.055 & 60.213 \\
2 & Aggression from coworkers & 0.173 & 0.096 & 54.819 \\
3 & Physical health & 0.126 & 0.117 & 45.346 \\
4 & Submissive reaction & 0.107 & 0.131 & 38.744 \\
5 & Assertive reaction & -0.075 & 0.137 & 32.506 \\
& Age & n.s. & 0.138 & 27.274 \\
\hline
\end{tabular}

Abbreviations as in Table 4.

variation in work satisfaction score in public service sector workers and $9.7 \%$ in nurse group. This means that satisfaction level derived from different aspects of work is inversely correlated with frequency of workplace aggression experiences. One may observe that coworkers' aggression contributes more to variance of scores in work satisfaction than clients'/patients' aggression does. This finding suggests that aggressive encounter with a coworker may be more abusive due to frequent and long term contact with the offender and may destroy the sense of personal security at workplace to the extent that significantly affects the employee's work satisfaction.

Relationships between three dimensions of burnout and aggression were also tested in multiple regression models (Tables 6-11). Depersonalisation has been reflected among other things in tendency to treat clients/patients as objects rather than people. This burnout dimension is correlated to aggression presented by clients/patients $(22.3 \%$ of explained variance in service sector and $7.7 \%$ in nursing) and to coworkers' aggression (17.6\% of explained

Table 8. Stepwise (forward) multiple linear regression model for relation between aggression from clients/patients and emotional exhaustion

\begin{tabular}{|c|c|c|c|c|}
\hline Step & Independent variable & Beta & $\mathrm{R}^{2}$ & $\mathrm{~F}^{*}$ \\
\hline \multicolumn{5}{|c|}{ Public service workers } \\
\hline 1 & Aggression from clients & 0.299 & 0.134 & 46.800 \\
\hline 2 & Physical health & 0.234 & 0.202 & 38.274 \\
\hline \multirow[t]{2}{*}{3} & Assertive reaction & -0.122 & 0.230 & 29.919 \\
\hline & Aggressive reaction, Submissive reaction, Sex, Age & n.s. & 0.246 & 13.815 \\
\hline \multicolumn{5}{|c|}{ Nurses } \\
\hline 1 & Physical health & 0.250 & 0.106 & 129.854 \\
\hline 2 & Aggression from patients & 0.214 & 0.145 & 93.001 \\
\hline 3 & Aggressive reaction & 0.182 & 0.189 & 84.687 \\
\hline 4 & Submissive reaction & 0.142 & 0.211 & 73.116 \\
\hline \multirow[t]{2}{*}{5} & Assertive reaction & -0.070 & 0.216 & 60.134 \\
\hline & Age & n.s. & 0.217 & 50.285 \\
\hline
\end{tabular}

Abbreviations as in Table 4. 
Table 9. Stepwise (forward) multiple linear regression model for relation between aggression from coworkers and emotional exhaustion

\begin{tabular}{|c|c|c|c|c|}
\hline Step & Independent variable & Beta & $\mathrm{R}^{2}$ & $\mathrm{~F}^{*}$ \\
\hline \multicolumn{5}{|c|}{ Public service workers } \\
\hline 1 & Aggression from coworkers & 0.266 & 0.127 & 44.176 \\
\hline 2 & Physical health & 0.225 & 0.181 & 33.380 \\
\hline \multirow[t]{2}{*}{3} & Assertive reaction & -0.129 & 0.208 & 26.371 \\
\hline & Age, Submissive reaction, Aggressive reaction, Sex & n.s. & 0.223 & 12.208 \\
\hline \multicolumn{5}{|c|}{ Nurses } \\
\hline 1 & Physical health & 0.248 & 0.113 & 130.713 \\
\hline 2 & Aggression from coworkers & 0.251 & 0.187 & 118.519 \\
\hline 3 & Submissive reaction & 0.151 & 0.216 & 94.389 \\
\hline \multirow[t]{2}{*}{4} & Aggressive reaction & 0.139 & 0.237 & 79.775 \\
\hline & Assertive reaction, Age & n.s. & 0.239 & 53.694 \\
\hline
\end{tabular}

Abbreviations as in Table 4.

variance and $3.9 \%$ respectively). The results show a bit stronger association between depersonalisation and aggression experienced from patients/clients. Probably this result is not the matter of real observable tendency but rather the consequence of the MBI structure where most items of depersonalisation scale deal with relationships between a responder and his/her clients/patients.

In the case of emotional exhaustion one may find differences in the relationship between this factor and experience of aggressive behaviours at work in the groups under study. Surprisingly, the emotional exhaustion-aggression relationship is much stronger in service sector than in health care. This tendency is observable irrespective of the source of aggression. Sense of emotional exhaustion is strongly affected by being the target both of clients' and coworkers' aggressive behaviours in service sector (13.4\% and $12.7 \%$ respectively). The same relationship is less evident but still statistically significant in the group of nurses (Tables 8 and 9).

The aggression experienced from coworkers has no significant effect on the personal accomplishment in both groups under study but there is a significant relationship between patients/clients aggression toward personnel

Table 10. Stepwise (forward) multiple linear regression modelfor relation between aggression from clients/patients and sense of personal accomplishment

\begin{tabular}{llccc}
\hline Step & \multicolumn{1}{c}{ Independent variable } & Beta & $\mathrm{R}^{2}$ & $\mathrm{~F}^{*}$ \\
\hline Public service workers & & & \\
1 & Assertive reaction & 0.377 & 0.202 & 76.787 \\
2 & Submissive reaction & -0.149 & 0.228 & 44.580 \\
3 & Aggression from clients & -0.113 & 0.249 & 33.233 \\
4 & Physical health & -0.118 & 0.263 & 26.737 \\
\multicolumn{7}{l}{ Aggressive reaction, Age, Sex } & n.s. & 0.271 & 15.797 \\
Nurses & & & \\
1 & Assertive reaction & 0.208 & 0.072 & 85.377 \\
2 & Submissive reaction & -0.120 & 0.091 & 54.856 \\
3 & Aggressive reaction & -0.103 & 0.102 & 41.330 \\
4 & Aggression from patients & -0.083 & 0.111 & 34.170 \\
5 & Age & 0.087 & 0.118 & 29.145 \\
6 & Physical health & -0.078 & 0.124 & 25.602 \\
\hline
\end{tabular}

Abbreviations as in Table 4. 
Table 11. Stepwise (forward) multiple linear regression model for relation between aggression from coworkers and sense of personal accomplishment

\begin{tabular}{llccc}
\hline Step & \multicolumn{1}{c}{ Independent variable } & Beta & $\mathrm{R}^{2}$ & $\mathrm{~F}^{*}$ \\
\hline Public service workers & & & \\
1 & Assertive reaction & 0.374 & 0.202 & 76.787 \\
2 & Submissive reaction & -0.166 & 0.228 & 44.580 \\
3 & Physical health & -0.137 & 0.246 & 32.814 \\
& Age, Aggressive reaction, Sex, & n.s. & 0.260 & 14.892 \\
\multicolumn{2}{l}{ Aggression from coworkers } & & & \\
Nurses & & & \\
1 & Assertive reaction & 0.202 & 0.074 & 85.612 \\
2 & Submissive reaction & -0.119 & 0.093 & 52.604 \\
3 & Aggressive reaction & -0.104 & 0.106 & 40.697 \\
4 & Physical health & -0.087 & 0.114 & 32.919 \\
5 & Age & 0.080 & 0.121 & 28.140 \\
& Aggression from coworkers & n.s. & 0.123 & 23.932 \\
\hline
\end{tabular}

Abbreviations as in Table 4.

and personal accomplishment. Employees who experienced higher aggression levels from patients/clients were characterised by lower level of personal accomplishment (Tables 10 and 11), and this kind of aggression explains $2.1 \%$ of variation in personal accomplishment score in public service workers and $0.9 \%$ in nurses' group.

Experiencing aggression at work has negative impact on well-being measured by means of the GHQ-28. The total
GHQ-28 score was affected by aggression experienced both from coworkers and patients/clients. In the regression models performed separately for health and service sectors, coefficients of variation shows that, in service sectors, aggression from clients contributes more to decreased mental health that it does in health sector, where aggression experienced from coworkers is a stronger predictor of negative changes in mental health status (Tables 12 and 13).

Table 12. Stepwise (forward) multiple linear regression model for relation between aggression from clients/patients and mental health (GHQ-28)

\begin{tabular}{llccc}
\hline Step & \multicolumn{1}{c}{ Independent variable } & Beta & $\mathrm{R}^{2}$ & $\mathrm{~F}^{*}$ \\
\hline Public service workers & & & \\
1 & Physical health & 0.336 & 0.180 & 66.499 \\
2 & Assertive reaction & -0.210 & 0.253 & 51.270 \\
3 & Aggression from clients & 0.233 & 0.305 & 44.126 \\
4 & Aggressive reaction & 0.180 & 0.337 & 38.132 \\
5 & Sex & -0.124 & 0.357 & 33.193 \\
& Submissive reaction, Age & n.s. & 0.350 & 24.408 \\
Nurses & & & \\
1 & Physical health & 0.392 & 0.195 & 265.669 \\
2 & Submissive reaction & 0.115 & 0.212 & 147.602 \\
3 & Aggressive reaction & 0.117 & 0.225 & 106.207 \\
4 & Aggression from patients & 0.114 & 0.237 & 85.206 \\
& Assertive reaction, Age & n.s. & 0.238 & 57.091 \\
\hline
\end{tabular}

Abbreviations as in Table 4. 
Table 13. Stepwise (forward) multiple linear regression model for relation between aggression from coworkers and mental health (GHQ-28)

\begin{tabular}{llccc}
\hline Step & \multicolumn{1}{c}{ Independent variable } & Beta & $\mathrm{R}^{2}$ & $\mathrm{~F}^{*}$ \\
\hline Public service workers & & & \\
1 & Physical health & 0.335 & 0.180 & 66.499 \\
2 & Assertive reaction & -0.213 & 0.253 & 51.270 \\
3 & Aggressive reaction & 0.162 & 0.289 & 40.778 \\
4 & Aggression from coworkers & 0.171 & 0.311 & 33.852 \\
5 & Sex & -0.128 & 0.333 & 29.823 \\
& Submissive reaction, Age & n.s. & 0.340 & 21.870 \\
Nurses & & & \\
1 & Physical health & 0.378 & 0.198 & 255.152 \\
2 & Aggression from coworkers & 0.187 & 0.236 & 160.196 \\
3 & Submissive reaction & 0.122 & 0.253 & 116.956 \\
4 & Aggressive reaction & 0.085 & 0.261 & 91.194 \\
& Age, Assertive reaction & n.s. & 0.262 & 61.056 \\
\hline
\end{tabular}

Abbreviations as in Table 4.

As the GHQ-28 enables estimation of four groups of mental health symptoms (somatic complains, anxiety and insomnia, disturbances in everyday functioning and depression), several regression models were tested to check which of groups of symptoms quoted above is most related to aggression experienced by subjects. The regression results for aggression by the source as the predictor of mental health problems are presented in Tables 14-19.

Aggression experienced from clients/patients accounts for $3.1 \%$ of variation in GHQ-A score (somatic complains) in service sector workers, and $0.8 \%$ in nurses, respectively. Bedides, $1.4 \%$ (service sector) $1.8 \%$ (health sector) of the GHQ-A score variance is accounted for by aggression from coworkers. From those results, it seems reasonable to assume that experience of aggressive behaviour results in increased prevalence and higher intensity of somatic complains (Tables 14 and 15).

Aggression, irrespective of its source, contributes also to symptoms of anxiety and insomnia (GHQ-B score). Aggression experienced from patients/clients accounts for $4.4 \%$ of variance in GHQ-B score in service sector

Table 14. Stepwise (forward) multiple linear regression model for relation between aggression from clients/patients and somatic symptoms (GHQ-A)

\begin{tabular}{llccc}
\hline Step & \multicolumn{1}{c}{ Independent variable } & Beta & $\mathrm{R}^{2}$ & $\mathrm{~F}^{*}$ \\
\hline Public service workers & & & \\
1 & Physical health & 0.337 & 0.168 & 61.206 \\
2 & Aggressive reaction & 0.184 & 0.220 & 42.669 \\
3 & Aggression from clients & 0.184 & 0.252 & 33.845 \\
$4 \quad$ Assertive reaction & -0.150 & 0.276 & 28.640 \\
\multicolumn{2}{l}{ Sex, Submissive reaction, Age } & n.s. & 0.292 & 17.502 \\
Nurses & & & \\
1 & Physical health & 0.373 & 0.161 & 211.471 \\
2 & Aggression from patients & 0.102 & 0.171 & 112.992 \\
3 & Aggressive reaction & 0.100 & 0.181 & 80.931 \\
& Submissive reaction, Assertive reaction, Age & n.s. & 0.184 & 41.023 \\
\hline
\end{tabular}

Abbreviations as in Table 4. 
Table 15. Stepwise (forward) multiple linear regression model for relation between aggression from coworkers and somatic symptoms (GHQ-A)

\begin{tabular}{llccc}
\hline \multicolumn{1}{c}{ Step } & Independent variable & Beta & $\mathrm{R}^{2}$ & $\mathrm{~F}^{*}$ \\
\hline Public service workers & & & \\
1 & Physical health & 0.335 & 0.168 & 61.206 \\
2 & Aggressive reaction & 0.169 & 0.220 & 42.669 \\
3 & Assertive reaction & -0.153 & 0.246 & 32.702 \\
$4 \quad$ Aggression from coworkers & 0.141 & 0.260 & 26.418 \\
& Sex, Submissive reaction, Age & n.s. & 0.278 & 16.299 \\
Nurses & & & \\
1 & Physical health & 0.370 & 0.164 & 203.418 \\
2 & Aggression from coworkers & 0.126 & 0.182 & 115.361 \\
3 & Aggressive reaction & 0.075 & 0.188 & 79.724 \\
& Submissive reaction, Assertive reaction, Age & n.s. & 0.191 & 40.560 \\
\hline
\end{tabular}

Abbreviations as in Table 4.

workers and $2.5 \%$ of this variance in nurses. The same tendency is observed for aggression experienced from coworkers (3.2\% and 3\% respectively), what means that being the object of aggression may affect mental health status by producing symptoms of anxiety and disturbing sleep (Tables 16 and 17).

Experiencing aggression may, to some extent, be related to the difficulties in everyday functioning. However, the results obtained for this category of symptoms are not as coherent as it was supposed. No effect of aggression experienced from coworkers on GHQ-C score was found in the group of service sector workers; however, aggression from clients was related to the significant increase of GHQ-C scores in this group of subjects. In nurses' group the opposite relation was found. Patients' aggression did not affect everyday functioning, but coworkers' aggression did (2.1\% of variance accounted for in GHQ-C scores) (Tables 18 and 19).

Frequency of contacts with aggressive patients/clients and coworkers is related to GHQ-D score (severe depression scale) in both groups under study, and percentage of variance explained does not exceed 3.5\% (Tables 20 and 21).

Table 16. Stepwise (forward) multiple linear regression model for relation between aggression from clients/patients and anxiety/insomnia (GHQ-B)

\begin{tabular}{llccc}
\hline Step & \multicolumn{1}{c}{ Independent variable } & Beta & $\mathrm{R}^{2}$ & $\mathrm{~F}^{*}$ \\
\hline Public service workers & & & \\
1 & Physical health & 0.280 & 0.132 & 46.801 \\
2 & Aggressive reaction & 0.178 & 0.185 & 34.271 \\
3 & Aggression from clients & 0.227 & 0.229 & 29.770 \\
4 & Assertive reaction & -0.155 & 0.254 & 25.569 \\
5 & Sex & -0.145 & 0.278 & 23.030 \\
\multicolumn{2}{l}{ Submissive reaction, Age } & n.s. & 0.289 & 17.228 \\
1 & Physical health & & \\
2 & Aggressive reaction & 0.321 & 0.133 & 168.981 \\
3 & Aggression from patients & 0.122 & 0.148 & 95.685 \\
$4 \quad$ Submissive reaction & 0.103 & 0.158 & 68.834 \\
& Age, Assertive reaction & 0.084 & 0.166 & 54.374 \\
\hline
\end{tabular}

Abbreviations as in Table 4. 
Table 17. Stepwise (forward) multiple linear regression model for relation between aggression from coworkers and anxiety/insomnia (GHQ-B)

\begin{tabular}{|c|c|c|c|c|}
\hline & Independent variable & Beta & $\mathrm{R}^{2}$ & $\mathrm{~F}^{*}$ \\
\hline \multicolumn{5}{|c|}{ Public service workers } \\
\hline 1 & Physical health & 0.272 & 0.134 & 46.801 \\
\hline 2 & Aggressive reaction & 0.153 & 0.185 & 34.371 \\
\hline 3 & Aggression from coworkers & 0.208 & 0.217 & 27.805 \\
\hline 4 & Assertive reaction & -0.160 & 0.244 & 24.163 \\
\hline \multirow[t]{2}{*}{5} & Sex & -0.157 & 0.272 & 22.333 \\
\hline & Submissive reaction, Age & n.s. & 0.278 & 16.330 \\
\hline \multicolumn{5}{|c|}{ Nurses } \\
\hline 1 & Physical health & 0.310 & 0.136 & 163.269 \\
\hline 2 & Aggression from coworkers & 0.166 & 0.166 & 102.906 \\
\hline 3 & Aggressive reaction & 0.091 & 0.175 & 73.331 \\
\hline 4 & Submissive reaction & 0.082 & 0.182 & 57.491 \\
\hline \multirow[t]{2}{*}{5} & Age & 0.062 & 0.186 & 47.066 \\
\hline & Assertive reaction & n.s. & 0.186 & 36.255 \\
\hline
\end{tabular}

Abbreviations as in Table 4.

Table 18. Stepwise (forward) multiple linear regression model for relation between aggression from clients/patients and social dysfunction (GHQ-C)

\begin{tabular}{llccr}
\hline Step & \multicolumn{1}{c}{ Independent variable } & Beta & $\mathrm{R}^{2}$ & $\mathrm{~F}^{*}$ \\
\hline Public service workers & & & \\
$1 \quad$ Physical health & 0.202 & 0.066 & 21.333 \\
2 & Assertive reaction & -0.192 & 0.116 & 19.780 \\
$3 \quad$ Aggression from clients & 0.118 & 0.129 & 14.919 \\
& Submissive reaction, Aggressive reaction, Age, Sex, & n.s. & 0.140 & 6.898 \\
Nurses & & & \\
$1 \quad$ Physical health & 0.281 & 0.099 & 121.229 \\
$2 \quad$ Submissive reaction & 0.098 & 0.111 & 68.319 \\
$\quad$ Assertive reaction, Aggression from patients, Age, & n.s. & 0.119 & 24.565 \\
$\quad$ Aggressive reaction & & & \\
\hline
\end{tabular}

Abbreviations as in Table 4.

\section{DISCUSSION AND CONCLUSIONS}

It has been assumed that exposure to aggression at work results in many problems that may, in consequence, affect employees' professional effectiveness and general health. We have also assumed that aggression towards coworkers presented by peers and supervisors, as the phenomenon reflecting quality of long term interpersonal relationships, may affect health and functioning of workers stronger than single incidents in short term contacts with patients or clients. This belief affected the way in which statistical analyses were performed. Analysing separately the effects of aggression from coworkers and clients/patients helped to reach a deeper insight into the relationship between aggression and health outcome.

Generally speaking, results of our study point to the negative consequences of being exposed to aggression at work, irrespective of its source. Employees subjected to workplace aggression are less satisfied with work, experience symptoms of burnout, and their general health is poorer. These results are supported by other studies [18-20]. 
Table 19. Stepwise (forward) multiple linear regression model for relation between aggression from coworkers and social dysfunction (GHQ-C)

\begin{tabular}{|c|c|c|c|c|}
\hline Step & Independent variable & Beta & $\mathrm{R}^{2}$ & $\mathrm{~F}^{*}$ \\
\hline \multicolumn{5}{|c|}{ Public service workers } \\
\hline 1 & Physical health & 0.218 & 0.066 & 21.333 \\
\hline \multirow[t]{2}{*}{2} & Assertive reaction & -0.191 & 0.116 & 19.780 \\
\hline & $\begin{array}{l}\text { Submissive reaction, Aggressive reaction, Age, Sex, } \\
\text { Aggression from coworkers }\end{array}$ & n.s. & 0.127 & 7.212 \\
\hline \multicolumn{5}{|c|}{ Nurses } \\
\hline 1 & Physical health & 0.263 & 0.100 & 115.079 \\
\hline 2 & Aggression from coworkers & 0.149 & 0.121 & 71.309 \\
\hline 3 & Submissive reaction & 0.106 & 0.133 & 53.044 \\
\hline \multirow[t]{2}{*}{4} & Age & 0.071 & 0.138 & 41.222 \\
\hline & Assertive reaction, Aggressive reaction & n.s. & 0.140 & 27.988 \\
\hline
\end{tabular}

Abbreviations as in Table 4.

Table 20. Stepwise (forward) multiple linear regression model for relation between aggression from clients/patients and depression symptoms (GHQ-D)

\begin{tabular}{|c|c|c|c|c|}
\hline & Independent variable & Beta & $\mathrm{R}^{2}$ & $\mathrm{~F}^{*}$ \\
\hline \multicolumn{5}{|c|}{ Public service workers } \\
\hline 1 & Physical health & 0.229 & 0.085 & 28.287 \\
\hline 2 & Assertive reaction & -0.187 & 0.141 & 24.788 \\
\hline 3 & Aggression from clients & 0.187 & 0.178 & 21.704 \\
\hline 4 & Sex & -0.100 & 0.194 & 18.013 \\
\hline \multirow[t]{2}{*}{5} & Aggressive reaction & 0.123 & 0.207 & 15.611 \\
\hline & Age, Submissive reaction & n.s. & 0.214 & 11.546 \\
\hline \multicolumn{5}{|c|}{ Nurses } \\
\hline 1 & Physical health & 0.269 & 0.103 & 126.354 \\
\hline 2 & Submissive reaction & 0.152 & 0.133 & 84.049 \\
\hline 3 & Aggressive reaction & 0.114 & 0.148 & 63.121 \\
\hline 4 & Aggression from patients & 0.096 & 0.156 & 50.630 \\
\hline \multirow[t]{2}{*}{5} & Assertive reaction & -0.057 & 0.160 & 41.578 \\
\hline & Age & n.s. & 0.162 & 35.162 \\
\hline
\end{tabular}

Abbreviations as in Table 4.

Some differences were found between clients'patients' and coworkers' aggression in terms of scope and power of associations with outcomes.

Level of satisfaction derived from work showed stronger association with aggression experienced from coworkers than from clients and patients. Job satisfaction refers to individual reactions to several work dimensions: work tasks, roles, relationships with others, skills utilisation and rewards. Many factors have been suggested in literature as being related to job satisfaction; among them quality of relationships within the organisation is one of most frequently quoted [21-24]. One may assume that aggressive coworkers are more "stable characteristics" of work environment to be faced everyday than clients/patients who are just "passing by". This finding suggests that aggressive encounter with a coworker may be more abusive due to frequent and long term contact with the offender and may destroy the sense of personal security at workplace to the extent that significantly affects employee's work satisfaction. Moreover, aggression from clients or patients usually 
Table 21. Stepwise (forward) multiple linear regression model for relation between aggression from coworkers and depression symptoms (GHQ-D)

\begin{tabular}{|c|c|c|c|c|}
\hline Step & Independent variable & Beta & $\mathrm{R}^{2}$ & $\mathrm{~F}^{*}$ \\
\hline \multicolumn{5}{|c|}{ Public service workers } \\
\hline 1 & Physical health & 0.227 & 0.085 & 28.287 \\
\hline 2 & Assertive reaction & -0.190 & 0.141 & 24.788 \\
\hline \multirow[t]{2}{*}{3} & Aggression from coworkers & 0.146 & 0.163 & 19.477 \\
\hline & Sex, Aggressive reaction, Submissive reaction, Age & n.s. & 0.200 & 10.584 \\
\hline \multicolumn{5}{|l|}{ Nurses } \\
\hline 1 & Physical health & 0.261 & 0.108 & 125.075 \\
\hline 2 & Submissive reaction & 0.162 & 0.141 & 84.874 \\
\hline 3 & Aggression from coworkers & 0.164 & 0.172 & 71.470 \\
\hline \multirow[t]{2}{*}{4} & Aggressive reaction & 0.092 & 0.182 & 57.247 \\
\hline & Assertive reaction, Age & n.s. & 0.184 & 38.692 \\
\hline
\end{tabular}

Abbreviations as in Table 4.

results in compassion of peers, and it is perceived as the organisational problem that should be solved. On the contrary, dealing with an aggressive coworker usually is employee's own business and produces the sense of unfairness and isolation. Probably these aspects are responsible for differences in the power of the relationship between different sources of aggressive behaviours at work and the level of work satisfaction.

Being subjected to workplace aggression, irrespective of its source, was generally associated with increase in burnout symptomatology. All but one dimension of burnout, namely personal accomplishment, were affected both by aggression from peers and clients/patients.

Aggression experienced from coworkers had no impact on sense of personal accomplishment in the studied professional groups; however, dealing with abusive clients/patients was related to this dimension of burnout. One possible explanations of this phenomenon is offered by the attribution theory [25]. It may be assumed that coworkers' aggressive behaviours are perceived as the expression of their stable personality traits and in that sense they have nothing to do with the sense of professionalism of the subjects. Moreover, dealing with abusive coworkers logically cannot be treated as the content of work, while ability to cope with aggressive clients/patients can.

In the presented study the relationship between experiencing aggression at work and well being was also confirmed; however, the strength of this association was a bit lower than in the case of burnout symptoms. Higher frequency of aggressive encounters at work correlates with poorer mental health status, what was also proved in other studies [18]. It may be also noted that the strength of relationship between aggression at work and outcomes differs depending on the studied professional group. Generally speaking, the effect of workplace aggression on the level of burnout and mental health status is stronger in public service workers. It seems that nurses are a bit more resistant to negative effects of aggression, especially when the patient is the source. The study does not allow for the explanation of this pattern of results but we may guess that nurses generally are better trained in dealing with difficult people, and do not take aggression from patients personally but rather perceive it as the consequence of patients' frustration or anxiety related to their health condition. Such approach to the problem and better coping with aggression may buffer the relationship between aggression and the studied outcomes, but further studies are needed to confirm this hypothesis.

The level of the aggression effects on dependent variables in the presented study was not very high. Obviously, experience of aggressive encounters at work explains only a part of variation of burnout, satisfaction or well-being scores, and many other factors, uncontrolled in the study, may contribute to changes in the level of analysed dependent variables. 
The results of the study highlight the problem of workplace aggression and its consequences that should be studied more systematically with the use of prospective research format. Especially in Poland, there is a need to develop and implement procedures for effective aggression management at workplace, indicating the professional risk groups and risk factors.

\section{REFERENCES}

1. Lanza ML. Nurses as patient assault victims: An update, synthesis and recommendations. Arch Psychiatr Nurs 1992;6: 163-71.

2. Fear and Violence in the Workplace: a Survey Documenting the Experience of American Workers. Minneapolis: Northwestern National Life, Employee Benefits Division; 1993.

3. Violence in the workplace. A Resource Guide. Registered Nurses' Association of Nova Scotia (RNANS); 1996. Available from: http://www.crnns.ca/documents/violence.pdf

4. Guidelines on coping with violence in the workplace. International Council of Nurses; 2007. Available from: http://www. icn.ch/guide_violence.pdf

5. Hoel H, Sparks K, Cooper CL. The cost of violence/stress at work and the benefits of a violence/stress-free working environment. Report Commissioned by the International Labour Organization (ILO): Geneva; 2001.

6. Barling J. The prediction, experience and consequences of workplace violence. In: VandenBos GR, Bulatao EQ, editors. Violence on the job. Washington D.C.: APA; 1998. p. 29-49.

7. Frolkey CA. Trauma in the workplace. Personnel J Suppl 1996;75(11):10-4.

8. Violence in the workplace comes under closer scrutiny. Issues in labor statistics. Washington DC: U.S. Department of Labor, Bureau of Labor Statistics; 1994.

9. Heiskanen M. Violence at Work in Finland - Trends, Contents, and Prevention. Journal of Scandinavian Studies in Criminology and Crime Prevention, 2007;8(1):22-40.

10. Kaufer S, Mattman JW. Workplace Violence: An Employer's Guide. Workplace Violence Research Institute (cited 2009 september 14) Available from: http://www.workviolence. com/articles/employers_guide.pdf
11. Diener E, Lucas RE, Oishi S. Subjective Well-Being: The Science of Happiness and Life Satisfaction. In: Snyder CR, Shane J Lopez, editors. Handbook of Positive Psychology. Oxford: Oxford University Press; 2002. p. 63-73.

12. Makowska Z, Merecz D. Polish adaptation of David Goldberg's General Health Questionnaires: GHQ-12 and GHQ-28. In: Dudek B. editor. Mental health assessment by means of David Goldberg's questionnaires. User's guide to the GHQ-12 and GHQ-28 questionnaires. Lódź: Instytut Medycyny Pracy; 2001. p.191-264 [in Polish].

13. Maslach C, Schaufeli WB. Historical and conceptual development of burnout. In: Schaufeli WB, Maslach C, Marek T., editors. Professional burnout: Recent developments in theory and research. New York: Taylor \& Francis; 1993. p. 1-16.

14. Maslach C, Jackson SE. Maslach Burnout Inventory manual. Palo Alto, CA: Consulting Psychology Press; 1986.

15. Pasikowski T.: Burnout Inventory - Polish Adaptation. In: Sęk H., editor. Work Burnout - Causes, mechanism, prevention. Warszawa: Wydawnictwo Naukowe PWN; 2000. p. 13548 [in Polish].

16. Spector PE. Job Satisfaction. Application, Assessment, Causes, and Consequences. London: Sage Publications, Inc; 1997.

17. Drabek M, Merecz D, Mościcka A. Exposure to workplace aggression in health care and public service sector. Med Pr 2007;58(4):299-306 [in Polish].

18. Hogh A, Engström-Henriksson M, Burr H. A 5-Year Follow-up Study of Aggression at Work and Psychological Health. Int J Behav Med 2005;12(4):256-65.

19. Evers W, Tomic W, Brouwers A. Aggressive behaviour and burnout among staff of homes for the elderly. Int J Ment Health Nurs 2002;11:2-9.

20. Cortina LM, Magley VJ, Williams JH, Longhout RD. Incivility in the workplace: Incidence and impact. J Occup Health Psychol 2001;6:64-80.

21. Kovner Ch, Brewer C, Wu Y, Cheng Y, Suzuki M. Factors Associated With Work Satisfaction of Registered Nurses. J Nurs Scholarsh 2006;38(1):71-9.

22. Krueger P, Brazil K, Lohfeld L, Edward HG, Lewis D, Tjam E. Organization specific predictors of job satisfaction: findings from a Canadian multi-site quality of work life cross-sectional survey. BMC Health Services Research 2002. Available from: http://www.biomedcentral.com/1472-6963/2/6 
23. Blegen M. Nurses' job satisfaction: a meta-analysis of related variables. Nurs Res 1993;42:36-41.

24. Billingsley BS. Predictors of Commitment, Job Satisfaction, and Intent to Stay in Teaching: A Comparison of General and Special Educators. The Journal of Special Education 1992;25(4):453-471.

25. Aronson E, Wilson TD, Alert RM: Social Psychology the Heart and the Mind. Poznań: Zysk i S-ka; 1997 [in Polish]. 
APPENDIX 1

\section{EXPOSURE TO WORKPLACE AGGRESSION QUESTIONNAIRE (EWAQ)}

Workplace aggression is becoming one of the serious problems of employees. Could you please tell us if you have experienced at your work any of situations listed below, and how often did they happen during last year.

While answering, please use the following response scale:

It does not apply to my workpost $\quad 0$

It has never happened 1

It happened couple times a year $\quad 2$

It happened almost each month $\quad 3$

It happened couple times a month $\quad 4$

It happened couple times a week $\quad 5$

It happened everyday 6

\section{Example:}

How often during last year did you face clients/patients who were:

\begin{tabular}{|l|l|}
\hline screaming at you & 5 \\
\hline threatening you while reclaiming own rights & 3 \\
\hline
\end{tabular}

How often during last year did you face clients/patients who were:

\begin{tabular}{|l|l|}
\hline screaming at you & \\
\hline threatening you while reclaiming their own rights & \\
\hline blackmailing you & \\
\hline trying to attack, hit you & \\
\hline perceived as dangerous for you & \\
\hline offending you, being foul-mouthed at the presence of your coworkers & \\
\hline offending you, being foul-mouthed at the presence of other clients/patients & \\
\hline assaulting you & \\
\hline
\end{tabular}


Could you please tell us if you have experienced at your work any of situations listed below, and how often did they happen during last year.

While answering, please use the following response scale:

It does not apply to my workpost $\quad 0$

It has never happened 1

It happened couple times a year $\quad 2$

It happened almost each month $\quad 3$

It happened couple times a month 4

It happened couple times a week $\quad 5$

It happened everyday 6

\section{Example:}

How often during last year did you face supervisors, co-workers or subordinates who were:

\begin{tabular}{|l|c|c|c|}
\hline & supervisors & co-workers & subordinates \\
\hline screaming at you & 4 & 5 & 0 \\
\hline threatening you while reclaiming own rights & 2 & 3 & 0 \\
\hline
\end{tabular}

How often during last year did you face supervisiors, co-workers or subordinates who were:

\begin{tabular}{|l|l|l|l|}
\hline & supervisors & co-workers & subordinates \\
\hline screaming at you & & & \\
\hline threatening you while reclaiming own rights & & & \\
\hline blackmailing you & & & \\
\hline trying to attack, hit you & & & \\
\hline perceived as dangerous for you & & & \\
\hline offending you, being foul-mouthed at the presence of your coworkers & & & \\
\hline $\begin{array}{l}\text { offending you, being foul-mouthed at the presence of other clients/ } \\
\text { patients }\end{array}$ & & & \\
\hline assaulting you & & & \\
\hline
\end{tabular}

